\title{
ANÁLISIS DE LA SITUACIÓN CANÓNICA QUE COMPORTAN LAS PENAS «LATAE SENTENTIAE» NO DECLARADAS
}

Fecha de recepción: 5 de septiembre de 2020

Fecha de aceptación: 28 de septiembre de 2020

RESUMEN: Una pena latae sententiae produce algunos efectos incluso antes de que la autoridad de la Iglesia se haya pronunciado sobre el presunto delito para el que esté establecida, de modo que la sujeción a los mismos descansa esencialmente sobre la voluntad del presunto autor. Con ello se materializa aquí un valor genuino del derecho canónico: su pretensión de obligar en conciencia. Por otro lado, diversas disposiciones del CIC contemplan una variedad de circunstancias en las cuales es lícito no someterse a esos efectos. Esto puede generar situaciones complejas para la comunidad eclesial y hacer pensar si en la práctica vale la pena mantener este tipo de penas.

PALABRAS CLAVE: atenuante; excomunión; eximente; peligro de muerte; pena latae sententiae; pena declarada/no declarada; prohibición; suspensión.

\section{An Analysis of the Canonical Situation Created by the Undeclared "Latae Sententiae» Penalties}

ABSTRACT: A latae sententiae penalty produces some effects even before the authority of the Church has ruled on the presumed crime for which it is established, so that

" Facultad de Derecho Canónico. Universidad Pontificia Comillas:

jlsgiron@comillas.edu; ORCID: https://orcid.org/0000-0002-6798-6324 
the subjection to those effects rests essentially on the will of the presumed author. With this, a genuine value of canon law is materialized here: its claim to oblige in conscience. On the other hand, various provisions of the CIC contemplate a variety of circumstances in which it is lawful not to submit to these effects. This can generate complex situations for the ecclesial community, and make one wonder whether in practice it is worth maintaining this type of punishment.

KEY WORDS: attenuating circumstance; excommunication; excusing circumstance; danger of death; latae sententiae penalty; declared/undeclared penalty; prohibition; suspension.

Como es sobradamente conocido por los iniciados en el derecho canónico penal, en él se contemplan las llamadas penas latae sententiae. Atendiendo al c. 1314, su peculiaridad es que se incurre en ellas ipso facto, en el mismo momento de cometerse el delito para el cual la pena se haya establecido de esta manera. La forma alternativa de establecer una pena que presenta el CIC es la que el mencionado canon denomina ferendae sententiae. En este caso, los efectos de la pena solo se dan a partir del momento en que la autoridad la impone a través de las debidas actuaciones. Este tipo de pena es el único que se encuentra en los demás ordenamientos jurídicos, siendo la pena latae sententiae un peculiaridad muy específica del derecho canónico ${ }^{1}$. El propio c. 1314 proporciona el criterio para saber cuándo una pena es de un tipo u otro, disponiendo que solo es latae sententiae cuando se establece así expresamente.

El CIC se refiere en distintas ocasiones las penas latae sententiae «declaradas» y a las «no declaradas», lo cual indica que estas penas pueden encontrarse en una u otra situación. Cánones como el 1341, el 1342 y el $1355 \$ 1.1$, dan a entender que las penas latae sententiae se declaran por el mismo cauce que se imponen las penas ferendae sententiae: mediante sentencia o decreto extrajudicial, lo cual viene a decir que se declaran a resultas de un proceso judicial o administrativo, respectivamente ${ }^{2}$. No

${ }^{1}$ Cf. Claudio Papale. "Latae sententiae (penas)". En Diccionario General de Derecho Canónico, dirigido por Javier Otaduy, Antonio Viana, y Joaquín Sedano, vol. IV, 975. Cizur Menor, Navarra: Universidad de Navarra-Thomson Reuters Aranzadi, 2012.

2 Otra peculiaridad del derecho canónico, que encontramos asimismo en el campo de lo penal, es que el proceso judicial no es el único tipo de procedimiento que se contempla, sino que está también la posibilidad del proceso penal administrativo; el cual se resolverá mediante un decreto que el CIC denomina repetidas veces «decreto extrajudicial». Ver, p. ej., los cc. 1342 y1720. 
se dice que estas penas se «imponen» por alguno de esos medios ya que, como hemos visto, se consideran impuestas ipso facto desde la comisión del delito. Podríamos decir que «declarar» una pena latae sententiae viene a ser que la autoridad de la Iglesia «aclara» de manera pública y para toda la comunidad que, efectivamente, a través de un proceso se ha verificado que la persona en cuestión cometió el delito y está sujeto a la pena latae sententiae establecida para el mismo ${ }^{3}$; no desde el momento en que ha sido declarada sino desde que cometió el delito, si bien la declaración añade a la pena efectos que no había cuando aún no estaba declarada.

\section{PENAS LATAE SENTENTIAE EN EL DERECHO CANÓNICO}

Atendiendo al CIC, se pueden establecer como penas latae sententiae las tres conocidas como censuras o "penas medicinales»: la excomunión (c. 1331), el entredicho (c. 1332) y la suspensión (cc. 1333 y 1334), pena que está prevista solo para los clérigos (obispos, sacerdotes y diáconos). Entre las llamadas "penas expiatorias» (c. 1336) pueden ser latae sententiae las penas de prohibición recogidas en el c. 1336 §1.3, pues así lo dispone el c. 1336 \$2. Salvo error u omisión, los delitos para los cuales se establece una pena latae sententiae en el CIC son los siguientes:

Pena de excomunión

C. 1364: apostasía, herejía o cisma.

C. 1367: profanación de las sagradas especies.

C. 1370 §1: agresión física al Romano Pontífice.

C. 1378 §1: absolución del cómplice en un pecado contra el sexto mandamiento.

C. 1382: consagración episcopal sin mandato pontificio (tanto el consagrante como el consagrado).

C. 1388 §1: violación directa del sigilo sacramental.

C. 1398: aborto ${ }^{4}$.

3 Cf. Mario Moscóni. “Declaración de penas”. En Diccionario General de Derecho Canónico, II, 898.

${ }^{4}$ En los delitos de los cc. 1367, 1370 §1, 1378 §1, 1382 y 1388 §1, la pena está «reservada a la Santa Sede», lo cual significa que solo ella las puede perdonar (en derecho penal canónico se emplea más bien el término «remitir»), cf. José Luis Sánchez-Girón. "Pena reservada”. En Diccionario General de Derecho Canónico, IV, 85-86. 
Pena de entredicho:

C. 1370 §2: agresión física a un obispo por cualquier fiel.

C. 1378 \$2.1: atentada eucaristía por un laico.

C. 1378 §2.2: el laico que atenta la absolución o escucha confesiones.

C. 1390 §1: el fiel (laico o clérigo) que denuncia falsamente ante un superior eclesiástico por solicitación en confesión.

C. 1394 §2: el religioso no clérigo (varón o mujer) que atenta matrimonio aunque sea meramente civil.

Pena de suspensión:

C. 1370 §2: agresión física a un obispo por parte de un clérigo.

C. 1378 \$2.1: el clérigo no sacerdote (se entiende, un diácono) que atenta realizar la acción litúrgica de la Eucaristía.

C. 1378 §2.2: fuera del caso del c. 1378 \$1, el clérigo que, no pudiendo absolver válidamente - un diácono o un sacerdote sin licencia (cc. 967-976) — atenta la absolución o escucha confesiones.

C. 1383: el que recibe la sagrada ordenación, sin las legítimas dimisorias, de un obispo del cual no es súbdito ${ }^{5}$.

C. 1390 §1: el clérigo que denuncia falsamente a un confesor ante superior eclesiástico por solicitación en confesión (incurre también latae sententiae en entredicho).

C. 1394 §1: el clérigo que atenta matrimonio aunque sea civil.

Pena expiatoria de prohibición del c. 1336 §1.3:

Según el c. 1383 el obispo que ordena a un súbdito ajeno sin las debidas dimisorias «incurre en la prohibición de ordenar durante un año» ${ }^{6}$. Sería la única pena latae sententiae de este tipo que se establece en el CIC.

${ }_{5}$ El canon no emplea la expresión latae sententiae sino que dice «queda ipso facto suspendido del orden que recibió»; pero, partiendo del propio canon 1314, se entiende que es un término equivalente. Para una afirmación de que se trata de una suspensión latae sententiae, cf., p. ej., Federico Aznar. "Comentario al canon 1384". En Código de Derecho Canónico. Edición bilingüe comentada por los profesores de Derecho Canónico de la Universidad Pontificia de Salamanca, 724. 15. a ed. Madrid: BAC, 1999.

6 Para una afirmación de que es una pena expiatoria latae sententiae, cf., Antonio Calabrese. "Comentario al canon 1383". En Comentario exegético al Código de Derecho Canónico, dirigido por Angel Marzoa, Jorge Miras, y Rafael Rodríguez-Ocaña,

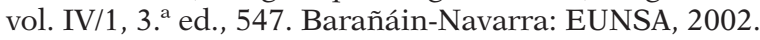


Nada impide que, fuera del Código, otras leyes universales establezcan penas latae sententiae. Es lo que podemos ver, por ejemplo, en el art. 5 de las vigentes normas sobre los delitos reservados a la Congregación para la Doctrina de la Fe del año 2010, que establece la pena de excomunión latae sententiae para quien atente conferir el orden sagrado a una mujer así como para la mujer que atente recibirlo ${ }^{7}$. Por su parte, en virtud del c. 1315 §1, la ley particular también puede tipificar delitos, que lo serán en el ámbito de su aplicación; y, a partir del c. 1319, es posible establecer una pena ejerciendo la potestad ejecutiva a través de un precepto penal que mande o prohíba algo a persona o personas determinadas, conminando mediante la pena el cumplimiento de lo mandado o prohibido ${ }^{8}$. Según el c. 1319 §2, en ambos supuestos hay que atenerse a las limitaciones de los cc. 1317 y 1318 , pero éstas no impiden que por uno u otro de estos medios se establezcan penas latae sententiae. En todo caso, el c. 1318 dispone con carácter general que estas penas no se establezcan si no es para delitos «que puedan causar un escándalo más grave o no puedan castigarse eficazmente con penas ferendae sententiae».

\section{EFECTOS DE LAS PENAS LATAE SENTENTIAE}

El c. 1331 §2 dispone cuáles son los efectos de la excomunión latae sententiae declarada, haciendo ver que el $§ 1$ recoge los que tiene la pena

7 Para estas normas, cf. Ecclesia 3529 (31 de Julio de 2010) 24-30. La excomunión latae sententiae está en este caso reservada a la Santa Sede (ver la nota 4). Este delito ya había sido tipificado en 2007 mediante un decreto de la Congregación para la Doctrina de la Fe que establecía para él esa misma pena, cf. AAS 100 (2008): 403. También se tipificó después del CIC (en 1988), estableciéndose la pena de excomunión latae sententiae, la captación por medios técnicos de lo que se dicen el confesor y el penitente en una confesión, así como su difusión por los medios de comunicación, cf. Enchiridion Vaticanum 11 (1988-1989): 844-845. Sin embargo, después de que en 2003 pasara a considerarse como un delito reservado a dicha Congregación —cf. Ius Ecclesiae 16 (2004): 320 - el art. 4 \$2 de las mencionadas normas del año 2010 cambió la pena, de modo que ya no es la excomunión latae sententiae. Para un mayor estudio, cf. Jose Luis Sánchez-Girón. "Delitos contemplados en las normas de graviorubus delictis del año 2010”. Estudios Eclesiásticos 85 (2010): 744-752, 761-763.

8 Sobre el precepto penal, cf., p. ej., John A. Renken. The Penal Law of the Roman Catholic Church. Commentary on Canons 1311-1399 and 1717-1731 and Other Sources of Penal Law. Ottawa: Saint Paul University, 2015, 63-66. 
cuando aún no se ha declarado; es decir, los que afectan ipso facto al sujeto desde el momento en que comete el delito. Sin ánimo de ser exhaustivos, estos efectos son:

- Prohibición de recibir los sacramentos.

- Prohibición de administrarlos y de tener cualquier participación activa en la misa o en cualquier ceremonia de culto.

- Prohibición de impartir sacramentales (no de recibirlos).

- Prohibición de ejercer potestad de régimen, derechos o privilegios.

- Prohibición de ejercer los cometidos propios de un oficio o cargo que tenga el excomulgado.

Cuando la pena se declara, estos efectos se mantienen y a ellos se añaden otros que empiezan a ser aplicables a partir del momento de la declaración. Entre otros estarían los siguientes:

- Se debe rechazar la participación del excomulgado en la misa u otra ceremonia de culto en la que pretenda participar; o cesarla si ya ha comenzado con su participación, a menos que obste una causa grave.

- Los actos de régimen que realice el excomulgado, además de ser ilícitos por estar prohibidos (esto es así desde la comisión del delito), son nulos.

- El excomulgado ya no puede recibir válidamente oficios, dignidades ni funciones ${ }^{9}$.

Conforme al c. 1332, los efectos del entredicho latae sententiae no declarado son los mismos que se prevén en el caso de la excomunión, pero solo en lo que se refiere a los sacramentos, sacramentales y ceremonias de culto; no a la potestad de régimen ni a los oficios, cargos, etc. Cuando la pena se declara, se añade el efecto ya indicado de tener que rechazar la participación en cualquier ceremonia litúrgica, en los mismos términos previstos para la excomunión ${ }^{10}$.

9 Para un estudio más detallado de los efectos de la excomunión, cf., p. ej., Angelo G. Urru. Punire per salvare. Il sistema penale nella Chiesa. Roma: Edizioni Vivere in, 2001, 96-102.

10 No es de extrañar que el entredicho se haya considerado como una «excomunión menor», cf. José Bernal. "Comentario al canon 1332". En Comentario exegético, IV/1: 362. Para mayor detalle sobre el entredicho, cf. ibid. 361-363. 
Según el c. 1333 §1, la pena de suspensión prohíbe «1. ${ }^{\circ}$ todos o algunos de los actos de la potestad de régimen; $2 .^{\circ}$ todos o algunos de los actos de la potestad de orden; $3 .^{\circ}$ el ejercicio de todos o algunos derechos o funciones inherentes a un oficio». Como se ve, la pena podría concretarse de multitud de maneras, según cuántos actos, derechos y funciones se prohíban de un tipo u otro. La ley o precepto puede establecer ya cuál es esa concreción en un determinado delito, de modo que, en caso de no hacerlo, se hará en la sentencia o decreto (c. 1334 §1); pero, como es lógico, si la pena es latae sententiae la ley o precepto deben precisar el alcance concreto de las prohibiciones. La ley puede hacer esto estableciendo que la pena es «suspensión latae sententiae sin añadir ninguna determinación o límite», en cuyo caso "produce todos los efectos enumerados en el c. $1333 \S 1$ » (así sucede en todas las suspensiones latae sententiae que hemos visto establecidas en el CIC); en cambio, esta posibilidad no se admite en el caso del precepto penal (c. 1334 §2).

Estas prohibiciones de la suspensión latae sententiae (concretadas de una u otra manera) producen efecto ipso facto desde la comisión del delito; es decir, aun cuando la pena no esté declarada. Si se llega a declarar, se añade que los actos de régimen realizados por el suspendido a pesar de estar prohibidos serán nulos además de ilícitos — cosa que ya serían desde que se comete el delito- pero solo si así lo ha dejado establecido la ley o el precepto (c. 1333 §2). Por tanto, mientras que en el caso de la excomunión latae sententiae declarada este efecto se produce siempre y automáticamente a partir de la declaración de la pena porque así lo dispone el CIC (c. 1331 §2, según vimos), en el caso de la suspensión latae sententiae se necesita que la ley o el precepto lo hayan previsto; de modo que, si no existe tal previsión, esos actos de régimen seguirían siendo válidos (aunque ilícitos) aun después de declararse la pena ${ }^{11}$.

Por lo que se refiere a la pena expiatoria de prohibición, el c. $1336 \S 1.3$, remitiéndose al §1.2, dispone que prohíbe ejercer actos de potestad, oficios, cargos, derechos, privilegios, facultades, gracias o títulos distintivos,

11 El c. 1332 §2 dice literalmente que, si hay esa previsión en la ley o el precepto, la nulidad de los actos se dará «post sententiam condemnatoriam vel declaratoriam». Sin embargo, no se ven razones para no admitir que se darán igualmente si la pena se impone o declara por decreto extrajudicial, cf. Woestman, 50. Para mayor detalle sobre los efectos de la suspensión, cf. W. Garczarek. "La sospensione penale (cc. 13331334) nel Codex Iuris Canonici del 1983”. Apollinaris 76 (2003): 359-399. 389-395. 
aun meramente honoríficos. Se entiende que la pena puede concretarse en más o menos prohibiciones de más o menos ámbitos de los indicados. El propio canon establece que «estas prohibiciones nunca son bajo pena de nulidad». De hecho, nada dice el CIC en este caso acerca de la nulidad de los actos de régimen que se realicen, a pesar de estar prohibidos, después de la declaración de la pena cuando esta es latae sententiae, como hemos visto que sí se prevé (de distinta manera en cada caso) para la excomunión y la suspensión. Por tanto, en esta pena expiatoria de prohibición, tanto cuando es latae sententiae y no está declarada como en el caso de llegar a declararse, los actos de régimen que se lleven a cabo a pesar de estar prohibidos serán ilícitos (precisamente porque la ley prohíbe hacerlos) pero siempre válidos en una y otra situación ${ }^{12}$. Tampoco contempla el CIC otros efectos añadidos para la pena declarada con respecto a la no declarada.

\section{CIRCUNSTANCIAS QUE EXIMEN DE LA PENA}

El hecho de establecerse en el CIC que los efectos de las penas latae sententiae se producen ipso facto con la comisión del delito, sin necesidad de un proceso ni de otras actuaciones de la autoridad eclesiástica, podría valorarse como una medida o planteamiento que tiene una singular y muy intensa carga sancionadora. Con todo, el Código contiene diversas disposiciones que llevarían a matizar o reconsiderar esa impresión.

En este sentido, cabe señalar que, con carácter general y no solo para las penas latae sententiae, el c. 1321 dispone que quien realiza una conducta tipificada como delito de manera no deliberada (es decir, no dolosa) sino "por omisión de la debida diligencia» solo queda sujeto a la pena establecida si así está previsto en la ley o el precepto. Por tanto, si no existe esa previsión, no hay pena para quien realiza de esa manera una conducta tipificada, lo cual se identifica en el mencionado canon con el término «imputable por culpa». Este planteamiento penal es también muy peculiar en el vigente derecho sancionador de la Iglesia con respecto al de otros ordenamientos, pues, en general, estos sí prevén que

12 Sobre la no nulidad de los actos de régimen que, en el caso de estas penas, se realicen a pesar de estar prohibidos, cf. Zbigniew Suchecki. Le privazioni e le proibizioni nel Codice di Diritto Canonico del 1983. Roma: Librería Editrice Vaticana, 2010, 94. 
esté penada la comisión culposa de un delito, aunque sea con una pena menor que el cometido con dolo ${ }^{13}$. En el CIC, solo hay un supuesto en el que está previsto penar esta forma de comisión (c. 1389 §2), lo cual es una muestra clara de la inclinación del vigente derecho sancionador de la Iglesia a excluir la pena en estos casos. No se trata de un delito para el cual se establezca una pena latae sententiae, de donde resulta que el CIC no prevé sancionar con una pena la comisión culposa de ninguno de los delitos para los cuales establece este tipo de pena.

Junto a esta disposición de carácter general, hay otras de igual naturaleza que también reducen las posibilidades de que alguien se encuentre sometido a una pena latae sententiae. Por un lado, está el c. 1322, al contemplar que «Se consideran incapaces de cometer un delito quienes carecen habitualmente de uso de razón, aunque hayan infringido una ley o precepto cuando parecían estar sanos». Por tanto, estas personas nunca quedarían sujetas a una pena aunque realizaran una conducta tipificada como delito ${ }^{14}$. Por otro lado, están las circunstancias recogidas en el c. 1323, pues la norma prevé que «no queda sujeto a ninguna pena quien, cuando infringió una ley o precepto» se encontrara en alguna de ellas. Son circunstancias que se consideran causas de inimputabilidad o eximentes de la pena ${ }^{15}$. Entre ellas está, por ejemplo, tener menos de 16 años, ignorar «sin culpa que se estaba infringiendo una ley o precepto» (es decir, sin haber omitido en conocerlo la diligencia que en cada caso pueda considerarse debida), o las que se conocen como «estado de necesidad», «caso fortuito» y «legítima defensa».

A esto se une que las circunstancias atenuantes del c. 1324, teniendo en principio el efecto de obligar a minorar la pena allí donde se verifiquen, en el caso de las penas latae sententiae comportan la exención de la pena (c. 1324 §3). De este modo, en ese tipo de penas tienen este

${ }^{13}$ Cf. José Luis Sánchez-Girón. "Penas medicinales y expiatorias: Una alternativa en la que profundizar entre otros aspectos penales del CIC". En El Código de Derecho Canónico de 1983, 274.

${ }_{14}$ Se trata de una presunción iuris et de iure, mientras que el c. 2201 del Código de 1917 la contemplaba como presunción que admite prueba en contrario (iuris tantum), cf. Bruno F. Pighin. Diritto penale canonico. Venezia: Marzianum Press, 2008, 169.

15 Para una distinción entre el diferente fundamento por el cual unas u otras circunstancias comportan que no haya pena, cf. Ángel Marzoa. "Comentario al canon 1323". En Comentario exegético IV/1: 307. 
efecto circunstancias como, por ejemplo, actuar careciendo de uso de razón por efecto de alcohol o drogas en el momento de la acción con tal de no haberlo provocado deliberadamente (c. 1325) o ignorar sin culpa «que la ley o el precepto llevaban aneja una pena»; es decir: aun conociendo que una conducta infringe una ley o precepto, si la pena establecida es latae sententiae esta no recae sobre quien realiza esa conducta en caso de que ignore sin culpa que hay una pena establecida para la infracción ${ }^{16}$.

En definitiva, hay numerosas posibilidades de que un fiel, a pesar de realizar una conducta tipificada como delito para el cual se establece una pena latae sententiae, no quede sujeto a la misma; pero es obvio que no deja de ser posible lo contrario. Ciertamente, bien puede darse el caso de alguien que realiza con plena deliberación (con dolo) una conducta tipificada sabiendo que es contraria a la ley o precepto y que hay una pena establecida para ella (en el caso de los clérigos, pero no solo, es más verosímil que se dé este conocimiento debido a la formación que reciben en derecho canónico), no dándose tampoco la circunstancia del c. 1322 ni ninguna eximente o atenuante de los cc. 1323 y 1324 . Con todo, conviene tener presente los límites que se dan en los efectos de las penas canónicas que pueden establecerse como penas latae sententiae.

\section{EFECTOS QUE SE EXCLUYEN Y REMISIÓN DE LA PENA}

Como ya se ha señalado, los actos de régimen que realice el excomulgado solo son inválidos, aparte de ilícitos por estar prohibidos conforme

16 De hecho, y como es lógico, no se establecen penas para todas las conductas prohibidas ni para la infracción de todas las normas que prescriben hacer o no hacer algo. Por poner solo algunos ejemplos, el CIC prohíbe consagrar una especie sin la otra en la Eucaristía o las dos fuera de ella (c. 927), pero ninguna de esas acciones está tipificada como delito (solo en caso de hacerlo con fines sacrílegos, según el art. 3 §2 de las normas para delitos reservados a la Congregación para la Doctrina de la Fe del año 2010, ver la nota 7). Asimismo, el CIC prevé para los padres la obligación de bautizar a sus hijos (c. 867), pero no establece una pena para quienes no lo hagan (sí la establece —c. 1366 - para «los padres [...] que entregan a sus hijos para que sean bautizados [...] en una religión acatólica»). Todo esto puede hacer más verosímil que, con respecto a una conducta tipificada como delito, haya no solo quien ignore sin culpa incluso que es contraria a la ley, sino también quien, aun sabiendo que la ley la prohíbe, ignore sin culpa que tiene establecida una pena. 
a la ley, cuando la pena se ha declarado. Si no está declarada, son ilícitos pero válidos. En el caso de la suspensión no declarada ocurre lo mismo, y el sumarse a la ilicitud la nulidad de tales actos después de la declaración depende de que esté previsto ese efecto en la ley o precepto. Por lo que se refiere a la prohibición del c. 1336, manteniendo que siempre son ilícitos, no serían nulos ni siquiera en el caso de que la pena se declare. Añadimos a estas limitaciones en los efectos de las penas señaladas que, en cuanto a la recepción o administración de los sacramentos que esté prohibida por cualquiera de ellas o por un entredicho, la pena en sí no comporta la nulidad del sacramento que se reciba o administre a pesar de la prohibición ${ }^{17}$. Por sí misma, esta hace ilícito que se haga una cosa u otra, pero no que el sacramento sea inválido ${ }^{18}$.

Sin duda, la ilicitud que comporta realizar lo que una pena prohíbe es un efecto de primer nivel desde el punto de vista jurídico. Desde esta perspectiva, en principio no se debería valorar como una medida frágil por el hecho de mantenerse la validez de los actos en los términos apenas indicados. Es más, la infracción de las prohibiciones que comportan las penas vendría a constituir, también en los casos donde los actos fueran válidos, el tipo penal del delito contemplado en el c. 1393, el cual establece que se puede imponer una pena justa a «quien infringe las obligaciones que le han sido impuestas como consecuencia de una pena» ${ }^{19}$. Con todo, de cara a valorar la situación en la que queda una persona sometida a las penas que estamos tratando, no es irrelevante señalar las limitaciones que se han apuntado.

En este sentido cabe añadir que, en el caso de la suspensión, el c. 1333 \$2.2 dispone que quien está sujeto a esta pena conserva el derecho de habitación que tenga por razón del oficio. Un párroco, por ejemplo,

17 Cf. Sánchez-Girón. "Penas medicinales y expiatorias", 280.

18 Según el c. 1109, es inválido el matrimonio asistido por el ordinario del lugar o el párroco que estén bajo una censura impuesta o declarada; pero el hecho de especificarlo esta norma permite concluir que es ella misma la que produce ese efecto y no tanto la propia pena en sí, pues en caso contrario no hubiera hecho falta precisarlo. Por otro lado, si la censura es latae sententiae y no está declarada, el matrimonio sería válido. Para la validez del sacramento de la penitencia es preciso que el sacerdote disponga de una licencia (c. 966, que habla de «facultad»), pero no es nada claro que la prohibición de administrar este sacramento provocada por una pena comporte que carezca de ella.

19 Sobre esta norma, cf., p. ej., Giuseppe di Mattia. "Comentario al canon 1393". En Comentario exegético IV/1: 573-574. 
seguiría teniendo derecho a vivir en la casa parroquial ${ }^{20}$. La norma no especifica que se refiera en particular a las penas ferendae sententiae o latae sententiae, por lo cual es aplicable a las dos y, por tanto, también a las latae sententiae no declaradas. El c. $1333 \S 1.3$ comprende entre los posibles efectos de una suspensión el de prohibir el ejercicio de derechos inherentes a un oficio; por lo cual, siendo la intención del CIC mantener en cualquier caso este derecho de habitación, se hace precisa esa disposición que así lo especifica.

No la encontramos en el caso de la excomunión, pero también es verdad que en los efectos de esta pena no hay una prohibición como la del c. 1333 §1.3. Sí está la de «desempeñar» oficios, ministerios o cargos (c. $1331 \S 1.3$ ), pero no hay razones suficientes para concluir que esto prohíba ejercer el derecho de habitación que estuviera aparejado a ellos ${ }^{21}$. Por tanto, es razonable considerar que también el excomulgado, en cualquier forma y situación de la pena, retendría ese ejercicio sin necesidad de que el CIC lo especifique concretamente ${ }^{22}$. En el caso de una pena expiatoria latae sententiae del c. $1336 \S 1.3$, cabe entender que solo estará prohibido el ejercicio de ese derecho cuando así se especifique. En el entredicho esta cuestión no tiene cabida, pues ya hemos visto que solo comporta algunos efectos de la excomunión que no afectan a este derecho de habitación.

Por otro lado, el c. $1333 \$ 3.3$ excluye también de los efectos prohibitivos de la suspensión la administración de los bienes que puedan pertenecer al oficio del suspendido, si bien en este caso solo cuando la pena sea latae sententiae. No se entiende bien que esta exclusión afecte también a la pena declarada ${ }^{23}$; pero, en todo caso, es claro que si no se ha procedido a su declaración el suspendido no tiene que abstenerse de administrar esos bienes; más bien se diría que el CIC cuenta con

${ }^{20}$ Cf. Woestman, 51.

21 El c. 18 impone aquí una interpretación estricta de la ley.

22 Otra cosa es que, en algunos casos, la ley disponga que, aparte de una de estas penas, el delito comporta la pérdida del oficio u oficios que se tengan, como es el caso de los cc. 1364 §1 y 1394 §1. En estos supuestos esa pérdida comportará, obviamente, que se pierde también el derecho de habitación que fuera inherente a un oficio.

${ }^{23}$ Cf. Velasio de Paolis y Davide Cito. Le sanzioni nella Chiesa. 2. ${ }^{\text {a }}$ ed. Roma: Urbaniana University Press, 2001, 204. 
que se ocupe de ello ${ }^{24}$. Cabe aplicar aquí los razonamientos anteriores acerca de la exclusión de este efecto en las demás penas sobre las que estamos tratando ${ }^{25}$.

También conviene tener presente que ni la excomunión, ni la suspensión, ni una pena expiatoria del c. $1336 \S 1.3$ (obviamente, tampoco el entredicho) comportan la pérdida del oficio o cargo sobre el cual recayeran sus efectos (lo mismo vale para los derechos, privilegios, etc., que menciona el citado canon). El CIC pide a quien esté sujeto a una de estas penas que se atenga a las prohibiciones de ejercer y desempeñar que en él se contemplan, pero las penas no comportan que deje de ser el titular del oficio o cargo. Para que dejara de serlo sería preciso proceder un acto jurídico específico de la autoridad competente que tuviera ese contendido; de modo que, si no lo hubiera, la persona podría volver a ejercerlo sin las limitaciones comprendidas en la pena una vez que esta cesara ${ }^{26}$.

En cuanto a esto último, es importante señalar que el CIC contempla la posibilidad de remitir cualquier pena; es decir, la posibilidad de que sea perdonada. En cuanto a las censuras (excomunión, entredicho y suspensión) el c. 1358 establece que se deben remitir cuando haya arrepentimiento verdadero y conveniente reparación de los daños y el escándalo, o al menos promesa fiable de hacerlo; disponiendo que, en cambio, no se pueden remitir mientras no se verifique este llamado «cese de la contumacia» (c. 1347). Esto no se prevé para las penas expiatorias,

${ }^{24}$ Cf. F. Aznar. "Comentario al canon 1333”. En Código de Derecho Canónico, 701.

25 Aún habría que añadir entre los efectos que no se dan en estas penas lo previsto en el c. 1333 \$3.1, según el cual la suspensión no afecta «a los oficios o la potestad de régimen que no están bajo la potestad del superior que establece la pena». Hay razones para pensar que la redacción del canon no es la más acertada, pero no es momento de abundar en ello. Para un mayor tratamiento de esta cuestión, cf. José Luis Sánchez-Girón. "El Superior que establece la pena: valoración crítica en clave exegética de los cc. 1333 §3.1 y 1338 §1”. Estudios Eclesiásticos 90 (2015): 683-700.

26 Sobre esta cuestión, cf. José Luis Sánchez-Girón. "Penas medicinales y expiatorias", 288-289. Como vimos (nota 22), los cc. $1364 \S 1$ y $1394 \S 1$ establecen penas latae sententiae de excomunión y suspensión, respectivamente, para los delitos que tipifican, añadiendo que, además, se produce la remoción de oficio del c. 194. Aplicando el mismo razonamiento que hicimos en la nota 18 , se puede decir que esto es una razón más para sostener que las penas, por sí mismas, no producen la pérdida del oficio. 
que en principio se mantendrán por un tiempo (c. 1336 §1) con independencia de lo anterior; pero nada impide que el arrepentimiento y reparación se considere como un motivo relevante para proceder a su remisión, aunque no exista la obligación de hacerlo ${ }^{27}$.

Los cc. 1354-1361 aportan detalladas disposiciones acerca de la remisión de las penas, entre las cuales está la posibilidad prevista en el c. 1357 de obtener «en el fuero sacramental» la remisión de las penas de excomunión y entredicho latae sententiae no declaradas ${ }^{28}$. Esta forma de remisión también se puede obtener para ambas penas y para la suspensión no declarada cuando el confesor es un obispo, si la pena no está reservada a la Santa $\operatorname{Sede}^{29}$ y ha sido establecida por ley (c. 1355 §2); y si es un canónigo penitenciario, o el sacerdote que cumpla esa función, incluso si la pena fue establecida mediante precepto (c. 509). Esto aparte, cualquier sacerdote puede remitir en la confesión sacramental toda censura, sin más matices ni excepciones, al fiel que se encuentre en peligro de muerte (c. 967); y el capellán también puede remitir en confesión "censuras latae sententiae no declaradas ni reservadas» en determinados lugares (c. $566 \S 2$ ).

En todos estos casos la remisión de la pena tiene eficacia jurídica también en el fuero externo, en el sentido de que la persona que se encontraba sujeta a ella ya no tiene la obligación de atenerse a sus efectos. Así se desprende de lo que establecía el c. 2251 del Código de 1917, el cual se hacía eco de la dificultad que supone el hecho de no poderse probar en el fuero externo que la pena ha sido remitida ante posibles exigencias de que la persona se atenga a ella.

${ }^{27}$ No en vano, las censuras se llaman también "penas medicinales», por tener esta característica de mantenerse mientras no se alcance la enmienda del delincuente, que es una finalidad primordialmente asociada a ellas; de modo que, alcanzado ese fin, se considera que no tiene sentido mantenerlas, cf. José Luis Sánchez-Girón. "Penas medicinales y expiatorias", 290-294. La importancia y efectos que la Iglesia quiere dar aquí al arrepentimiento (dando cauce a un destacado valor evangélico con una normativa penal inédita en otros ordenamientos jurídicos) encaja con lo ya expresado en el sentido de que estas penas posibilitan retornar a la situación que había antes de quedar la persona sujeta a ellas.

${ }_{28}$ Sobre esta cuestión, cf. Roberto Aspe. "El 'caso urgente' para la remisión de las censuras en la normativa canónica actual”. Periodica 101 (2012): 259-198.

${ }^{29}$ Ver la nota 4. 


\section{SUSPENSIÓN DE LOS EFECTOS DE LAS PENAS}

Según el c. 1335, que se refiere a las censuras y es aplicable a las penas expiatorias de prohibición (c. 1336 §3), cuando una u otra de estas penas «prohíbe celebrar los sacramentos o sacramentales, o realizar actos de régimen, la prohibición queda suspendida para atender a los fieles en peligro de muerte». Se entiende que no estamos, en absoluto, ante una cesación de la pena. La persona que está sometida a ella permanece en esa misma situación. Lo que se produce es la suspensión de algunos de sus efectos (a los que no tendrá que sujetarse esa persona), que serán solo los que señale la norma y ninguno más, y solo en las circunstancias que se indiquen. Fuera de ellas se mantienen todos los efectos de la pena ${ }^{30}$. Por lo que a esta norma concierne, se trata concretamente de poder administrar los sacramentos y los sacramentales a un fiel que está en peligro de muerte y de poder realizar para él actos de régimen, de modo que cualquier otro efecto de la pena se mantiene incluso en esa circunstancia y, fuera de ella, se mantienen todos.

La disposición, que vale tanto para las penas ferendae sententiae como para las latae sententiae declaradas o no declaradas, tiene un estimable valor de cara al fin primordial del derecho canónico de atender a la salus animarum de los fieles (c. 1752), evitando que una persona en situación tan delicada como es estar en peligro de muerte se vea privada de medios relevantes para ese fin (un sacramento, una dispensa, una gracia, etc.) por el hecho de que una pena prohíba proporcionarlos a quien de otro modo podría hacerlo ${ }^{31}$. La suspensión de los efectos de la pena comporta que, en la situación indicada, es lícito realizar los actos prohibidos. Aquel de ellos que hubiera sido ilícito pero válido de no ser por esta norma (por ejemplo, la administración de un sacramento), ahora pasa a ser lícito además de válido. No es banal indicarlo, precisamente por lo ya comentado sobre la relevancia canónica que debe darse a la ilicitud del acto prohibido que no obstante fuera válido. Carecería de rigor y de altura jurídica permitir algo ilícito bajo la consideración de que, a pesar de ello, sería válido.

${ }^{30}$ Cf. de Paolis y Cito, 231. Esta indicación vale igualmente para los efectos y circunstancias que se verán seguidamente.

31 Sobre el sentido de favorecer la salus animarum que tiene el c. 1335 (en esta disposición y en la que se verá seguidamente), cf., p. ej., Antonio Calabrese. Diritto penale canonico. 2. ${ }^{\mathrm{a}}$ ed. Città del Vaticano: Libreria Editrice Vaticana, 1996, 127. 
Teóricamente, el peligro de muerte —-máxime al considerarse que no consiste solo a estar in articulo mortis - podría proporcionar en algunos casos un gran número de ocasiones en las que se aplicaría la suspensión de la pena prevista en el c. 1335 (pensemos en el capellán de un hospital o incluso en un párroco), pero no deja de ser una más de las muchas situaciones que pueden darse en la Iglesia ${ }^{32}$. Ahora bien, el propio c. 1335 presenta otra disposición con mayor potencial de generar ocasiones en las cuales se daría ese efecto con respecto a las penas que estamos estudiando cuando no estén declaradas. Dice la norma que, en este caso, «se suspende también la prohibición» de celebrar sacramentos o sacramentales o de realizar actos de régimen «cuantas veces un fiel pide» una u otra cosa, añadiendo que "es lícito pedirlo por cualquier causa justa».

Esta disposición puede valorarse nuevamente como una medida en favor de la salus animarum, ya que posibilita a los fieles pedir actos y obtenerlos (aunque no estén en peligro de muerte) incluso de aquel que, si no fuera por esta norma, estaría obligado a denegárselos a causa de una pena que le prohíbe realizarlos. De nuevo tenemos una circunstancia por la cual, ahora en un número relevante de casos posibles, es lícito realizar actos que de otro modo serían ilícitos (valen aquí las consideraciones anteriores sobre la importancia jurídica que esto tiene, incluso para los actos que serían válidos aun siendo ilícitos). Por tanto, estamos nuevamente ante una norma que, a pesar del énfasis penalizador que pueda verse en unas penas que se imponen ipso facto, supone otra mitigación de los efectos que tienen en la práctica las penas latae sententiae cuando no están declaradas.

Cabe señalar que esta suspensión de los efectos de la pena no declarada tendría otra consecuencia en favor de quien estuviera sujeto a ella: evitar que se vea forzado a, cuando menos, generar sospechas de que ha cometido un delito. En efecto, si a causa de la pena tuviera que denegar el acto a quien se lo pide sin saber que ha realizado una acción delictiva, para preservar esta situación y evitar infamarse no alegaría la verdadera razón por la cual deniega el acto; pero la propia denegación podría generar sospechas sobre cuál es el motivo. Ciertamente, cuando se trate de

32 En el Código el peligro de muerte comprende también la situación de estar en riesgo grave de perder la vida; por ejemplo, una grave enfermedad, una cirugía de riesgo, calamidades de índole natural, epidemias, etc., cf. Ana Lía Berçaitz de Boggiano. "Peligro de muerte". En Diccionario General de Derecho Canónico IV: 66. 
una pena ferendae sententiae que ha sido impuesta o de una latae sententiae que ya ha sido declarada, no tendría sentido prestar atención a ese interés de no forzar a revelar o generar sospechas, pues habrá habido un proceso que ha impuesto o declarado la pena, lo cual hace que esto sea público y pueda ser conocido ${ }^{33}$. Se entiende, pues, que esta segunda disposición del c. 1335 no ampare a las penas impuestas o declaradas y se limite a las no declaradas.

En todo caso, el texto no condiciona la suspensión de los efectos de la pena a que el solicitante del acto ignore que aquel a quien lo pide ha hecho algo que responde al tipo penal de un delito para el cual está establecida una pena latae sententiae, ni a que esto lo desconozcan más o menos personas. Solo pide que la pena no esté declarada, situación jurídica que persiste mientras la autoridad de la Iglesia no proceda a su declaración. El texto no da elementos para concluir que, si permanece oculto a los demás el hecho de que alguien es el autor de una conducta castigada con pena latae sententiae, lo previsto en él para la pena no declarada decaiga en caso de que ese hecho pase a ser conocido por más o menos personas; ni siquiera en el supuesto de que sea el propio solicitante del acto el que lo conozca ${ }^{34}$.

Si el c. 1335 mitiga tan notablemente los efectos de las penas que estamos tratando, otro tanto cabe decir del c. 1352. Atendiendo al mismo (§1), «Si una pena prohíbe recibir sacramentos o sacramentales, la prohibición queda en suspenso durante todo el tiempo en el que el reo se encuentre en peligro de muerte», lo cual es aplicable tanto a las penas impuestas ferendae sententiae como a las latae sententiae estén declaradas o no. Se entiende claramente que, una vez más, es el fin de la salus animarum lo que de forma directa e inmediata da sentido y valor a la norma. En este caso no se favorece ese fin posibilitando que quien está en peligro de muerte reciba los sacramentos y los sacramentales de quien no podría administrárselos por prohibírselo pena —esto es lo que posibilitan los cc. 1335 y el 1338 para las penas objeto este trabajo, como ya se ha indicado- sino por ser el propio fiel en peligro de muerte quien tiene prohibido recibirlos a causa de una pena y permitir la norma que los reciba, mientras permanezca en esa situación, no solo válidamente,

${ }^{33}$ Cf. de Paolis y Cito, 230.

${ }^{34}$ Sobre este párrafo y el anterior, cf. ibid., 205. 
sino también lícitamente (vale de nuevo lo que ya se ha dicho sobre la importancia que esto tiene).

Si bien son aplicables aquí las consideraciones que se hicieron acerca del c. 1335, en el sentido de que el peligro de muerte no deja de ser una entre tantas situaciones posibles, lo cierto es que el c. 1352 también contiene otra disposición que puede llevar en mayor medida a la suspensión de los efectos de la pena siempre que sea latae sententiae. Dice el §2: "Queda en suspenso total o parcialmente la obligación de observar una pena latae sententiae que no haya sido declarada ni sea notoria en el lugar donde se encuentra el reo, en la medida en que éste no pueda observarla sin peligro grave de escándalo o infamia». De nuevo estamos ante una norma con la cual se pretende evitar que el cumplimiento a una pena pueda generar a quien esté sometido a ella el perjuicio de infamarse, dando a los hechos en los cuales tendría su causa una notoriedad que no hayan adquirido en un determinado lugar ${ }^{35}$.

Como se dijo acerca de la segunda disposición del c. 1335, no tiene sentido plantearse esto si se ha dado la declaración de la pena. De hecho, el c. 1352 §2 solo se refiere a la no declarada. Por otro lado, la norma no especifica en este caso algunos efectos que serían los únicos a los cuales no habría que someterse, ni se limita a exigir únicamente que la pena no esté declarada. Ahora esos efectos podrían ser cualquiera, algunos o todos, dependiendo de que su observancia comporte un grave peligro de escándalo o de que la persona quede infamada por desvelarse los referidos hechos o generarse sospechas sobre ellos; de modo que si ya existe la notoriedad a la que se refiere la norma, no se suspendería ningún efecto de la pena y habría que atenerse a todos ellos ${ }^{36}$.

\section{COMPLEJIDAD EN LA APLICACIÓN PRÁCTICA}

Quizá ya se haya podido apreciar hasta aquí que la normativa codicial referida a las penas latae sententiae no declaradas, a pesar de no ser muy extensa, puede resultar compleja de aplicar en la práctica. Pensemos, por

35 Quizá el canon hubiera hecho mejor refiriéndose no tanto a la notoriedad de la pena cuanto a la del hecho que responda a un determinado tipo penal para el que esté establecido la pena.

36 Sobre las consideraciones acerca del c. 1352 §2, cf. Pighin, 230-231. 
ejemplo, en un párroco que deliberadamente ha revelado a otra persona la identidad de un penitente y algún pecado grave que le ha confesado en el sacramento de la penitencia. Esto responde a la violación directa del sigilo sacramental ${ }^{37}$, para la cual se establece en el c. 1388 §1 la pena de excomunión latae sententiae reservada a la Santa Sede ${ }^{38}$. En el mismo momento de hacer esa revelación el párroco queda sujeto a los efectos que tiene esta pena cuando no está declarada, pues es obvio que de momento no lo está y así permanecerá mientras la autoridad competente no proceda a su declaración.

En su versión más rigurosa, y sin ánimo de detallar ahora todos los efectos de la excomunión, el c. 1331 §1 impone al párroco abstenerse de ejercer su oficio y, más allá incluso de cuanto que esto ya lo requiere, de administrar los sacramentos y hasta de recibirlos. Se entiende que, generando una tal situación canónica, se abrigue el propósito de que el párroco se apresure a recapacitar sobre lo que ha hecho y, sinceramente arrepentido, repare el daño como sea posible y solicite el perdón de la pena - que, como vimos, en este caso sería obligado conceder- para retornar al estado de cosas anterior a la misma ${ }^{39}$. No obstante, una completa valoración de la normativa codicial no puede dejar de plantearse lo que se derivaría de ella misma mientras no se alcanzara ese objetivo.

Entrando en ello, tenemos que en principio la ley reclama al párroco esa "congelación" de su actividad apenas mencionada (no visitar a los enfermos, no atender a las catequesis, no celebrar misa ni confesar, no atender consultas en el despacho, etc.); pero, como ya se vio, le permite al tiempo seguir ocupando la casa parroquial y hasta le pide que se encargue de la administración de los bienes de la parroquia, manteniéndolo como titular canónico del oficio. No parece exagerado decir que la situación es cuando menos atípica. No se ve que pueda hacerse compatible cada cosa sin que el conjunto resulte extraño y complejo de aplicar. Bien es verdad que eso mismo podría colaborar más aún al arrepentimiento que se quiere favorecer, pero hemos de seguir planteando la eventualidad de que este paso no se produzca; cosa que cuando menos puede suceder

37 Cf. p. ej. Woestman, 132.

38 Ver, de nuevo, la nota 4.

39 Cf. Pighin, 189; Naaman Boutros. Aspetti giuridico-teologici delle sanzioni e delle pene canoniche alla luce dell'Ecclesiologia di comunione del Concilio Ecumenico Vaticano II. Roma: Pontificia Università Lateranense, 2002, 189-190. 
durante algún tiempo. Lo que encontramos aquí, en cambio, son diversas disposiciones que, con una u otra finalidad, pueden acabar atemperando notablemente la aparente incomodidad.

Mientras la pena no esté declarada y, en el caso planteado, la persona a la que reveló la confesión no diga nada a nadie, el párroco queda amparado por el c. 1352 §2. Como vimos, en una circunstancia así esta norma le permitiría desempeñar las funciones de párroco que, en caso de no ejercerlas, pudieran generar escándalo o levantar sospechas de que se abstiene de realizarlas por algo grave que ha hecho. Podría tratarse, por ejemplo, de no dejar de celebrar las misas parroquiales ni de atender el confesionario en las horas habituales ni de asistir a los enfermos y a reuniones importantes ya fijadas (añádanse cosas semejantes), porque otra cosa produciría perplejidad entre los fieles e incluso sospechas que le infamaran. Pero, ¿dónde estaría la frontera entre lo que entrañan esos riesgos y lo que no? Seguramente no es fácil trazarla; y no sería extraño que, ante ello, el párroco fuera considerando que son más y más cosas las que puede hacer al amparo del citado canon. Con ello, se vería diluido o cuando menos mermado el objetivo de que la incómoda situación diseñada por el c. 1331 §1 le mueva a salir de ella solicitando el perdón de la pena.

Por otro lado, supongamos que ésta acaba declarándose y que, aparte de perderse el cobijo del c. 1352 §2, se plantea revisar la conducta del párroco desde que violó el sigilo sacramental por ver si constituye delito de quebrantamiento de las obligaciones de una pena (c. 1393, como vimos); en este supuesto, de la excomunión no declarada. Sin duda que, en muchos casos, sería complicado construir una base probatoria con la suficiente solidez como para formular una acusación por ese delito - especialmente teniendo en cuenta, precisamente, que lo que hiciera al amparo del c. 1352 §2 no sería quebrantamiento de la pena- lo cual podría apuntar a que no es un medio tan eficaz como pudiera pensarse para favorecer el cumplimiento de las penas latae sententiae no declaradas.

Otra situación que podría darse es que, sin estar la pena declarada, se difundiera entre la comunidad que el párroco violó el sigilo sacramental. Podría ser, por ejemplo, porque la persona a quien hizo la revelación lo va dando a conocer, o bien porque hace un uso de la información que lleva al penitente a concluir o sospechar que el párroco se la reveló y manifiesta a otros esas conclusiones o sospechas; o podemos alterar el supuesto de partida y ponernos en el caso de que la revelación se hizo ante varias o muchas personas. Como quiera que sea, habiendo esta difusión 
y notoriedad, es probable que muchos fieles se alejaran del párroco y del desempeño de su oficio; pero él seguiría siendo el titular del mismo, podría habitar en la casa parroquial, deberá administrar los bienes y, al amparo del c. 1335, aún podría administrar los sacramentos (no solo de manera válida, sino también lícita) y hacer lícita y válidamente actos de régimen para fieles que se lo pidan (aun fuera del peligro de muerte), como podrían ser aquéllos que no están en la línea de los que lo rechazan o los que no tienen noticia alguna de que haya podido violar el sigilo sacramental. Esto podría amparar no solo peticiones explícitas y concretas, sino quizá también mantener las misas parroquiales y las confesiones en sus horarios establecidos mientras sigan acudiendo fieles, administrar otros sacramentos y quizá más actividades ${ }^{40}$.

En cualquier caso, habría una situación confusa en la comunidad; y en cuanto a la pérdida de lo previsto en el c. 1352 §2, aún habría que considerar que, en realidad, nadie puede saber a ciencia cierta si el párroco está excomulgado o no, pues pudiera ser, por ejemplo, que revelara la identidad del penitente y sus pecados estando privado de uso de razón por encontrase ebrio o bajo otra circunstancia que, como ésta, lleva a la exención de una pena latae sententiae según ya hemos visto. Como se dijo, el c. 1352 §2 dispone que se suspende total o parcialmente la obligación de atenerse a los efectos de «una pena latae sententiae, que no haya sido declarada ni sea notoria en el lugar donde se encuentra el reo», pero se diría que la correcta aplicación del texto requiere que la pena recaiga realmente sobre la persona en cuestión, y ya vimos que hay múltiples motivos por los cuales esto puede no verificarse aunque se haya cometido una conducta tipificada como delito ${ }^{41}$.

Por ello, al referirse el canon a la notoriedad de la pena, y no a otra cosa, la situación que se genera en la comunidad eclesial puede ser confusa; si

${ }^{40}$ Recordemos, en particular, que el c. 1109 solo provocaría la invalidez del matrimonio asistido por el párroco si la pena está declarada; de modo que, si no lo está, no se produciría ese efecto con independencia de otras circunstancias.

41 Saliendo del caso del párroco, pensemos, por ejemplo, que la inmensa mayoría de las mujeres que abortan, o de las personas que de una u otra forma cometen este delito, seguramente ignoran sin culpa (sin omitir la diligencia que cabe exigirles en conocer la ley) que el aborto está prohibido en el derecho canónico, sobre lo cual ya dijimos que les eximiría de la pena. Y suponiendo que este eximente no fuera aplicable, aun sería lo más probable que se diera la atenuante de ignorar sin culpa que hay una pena establecida para el aborto, lo cual comportaría, como vimos, el mismo efecto de eximir de la pena. 
no es que, en rigor canónico, está llamada a serlo en cualquier caso. Bajo este punto de vista, podemos decir que, a falta de la declaración de la pena - de un pronunciamiento por parte de la autoridad a través de un proceso y las debidas actuaciones- nadie está en condiciones de asegurar, ni siquiera un grupo de fieles más o menos avezados en el derecho canónico, que el párroco esté sometido a pena alguna y no se den una o más de las muchas circunstancias por las cuales no habría lugar a la pena; por no decir que tampoco puede nadie asegurar que haya cometido un delito y no que esté siendo objeto de una falsa acusación ${ }^{42}$. Otra cosa es que el conocimiento de los hechos que se tenga esté llamado a motivar en los fieles la comunicación de lo que se sepa a la autoridad competente, y ésta emprenda las actuaciones previstas de modo que la situación se llegue a esclarecer y se acabe clarificando a qué hay que atenerse.

No estando declarada la pena, podría darse la circunstancia, por ejemplo, de que algunos fieles, teniendo un conocimiento un tanto vago del CIC y alguna información que dan por segura de que el párroco violó el sigilo sacramental, se sientan indignados al ver que, por ejemplo, va a presidir una eucaristía o una exposición del Santísimo o una procesión, y pretendan impedirlo. Ciertamente, si el párroco está realmente excomulgado, es ilícito que haga esas acciones porque lo prohíbe el c. 1331 $\S 1$. Sin embargo, como se vio más arriba, el rechazo a que las realice y el impedirlo en caso de que vaya a hacerlo está previsto en el c. 1331 §2.1 para el supuesto de que la pena se haya declarado ${ }^{43}$. Es más, aunque la información que tienen estos fieles se hubiera difundido ampliamente entre la comunidad, e incluso en caso de que fuera cierta y el párroco hubiera realmente incurrido ipso facto en la pena de excomunión, éste podría sostener que nadie tiene derecho a impedirle lo que pretende hacer por no estar declarada la excomunión, pues esto es lo único que según el CIC hace entrar en vigor ese efecto del c. 1331 \$2.1 (otra cosa sería que,

${ }^{42}$ Cf. Mosconi, "Declaración de penas", 898. El autor ofrece en el conjunto de su citada contribución un certero tratamiento de distintas cuestiones que han salido o saldrán en ésta.

${ }^{43}$ La exposición del Santísimo y una procesión son ceremonias de culto y podrían entrar en la amplia concepción que se tiene de los sacramentales (SC 79), cf. Estanislao Olivares. "Sacramentale". En Nuovo Dizionario di Diritto Canonico, dirigido por Carlos Corral, Velasio de Paolis, y Gianfranco Ghirlanda, 939. 2. ${ }^{\text {a }}$ ed. Cinisello Balsamo-Milano: Edizioni San Paolo, 1996. Por tanto, podemos considerar que les afectan las disposiciones mencionadas del c. 1331. 
si realmente quedó excomulgado, su acción sea ilícita por quebrantar el c. $1331 \S 1)$.

Siempre podría alegar también que él sabe, y otros no, que se dieron circunstancias por las cuales quedó exento de la pena (cosa que puede ser verdad, como ya dijimos) o incluso que ya ha obtenido el perdón de la pena en el fuero sacramental ${ }^{44}$. Nadie estaría en condiciones de sostener con certeza nada que, al amparo de la normativa canónica, diera una razón jurídica definitiva que prevalezca sobre estas posibles alegaciones del párroco.

Más allá de lo que pueda dar de sí un ejemplo como el que estamos viendo, habría tantos más que podrían ilustrar la idea de que la normativa canónica sobre las penas latae sententiae no declaradas aboca a situaciones prácticas complejas; y parece que algunas se han debido de verificar. De hecho, dejando aparte la de poder atender a un fiel en peligro de muerte, las posibilidades que ofrece el c. 1335 han llegado a generar confusión y necesidad de aclaraciones que se han hecho concretas y explícitas. Así, el Pontificio Consejo para los Textos Legislativos tuvo que hacer en 1997 una declaración con respecto a esta norma aplicada al caso del clérigo que ha cometido atentado matrimonio y por ello, según ya vimos, ha incurrido ipso facto en la pena de suspensión establecida para este delito en el c. $1394 \$ 1$ como pena latae sententiae. La declaración dispone que, en ese caso, aun cuando la pena no esté declarada, se considera que no hay causa justa alguna para que los fieles pidan a ese sacerdote un sacramento, sacramental o acto de régimen, supuesto que es bien conocida la situación irregular en la que éste se ha colocado ${ }^{45}$. Se ve que el Pontificio Consejo descarta de antemano la aplicación del c. 1352 §2, y se centra en excluir este caso de las posibilidades previstas en el c. 1335 para las penas no declaradas.

En todo caso, esta intervención del Pontificio Consejo es una muestra de que, cuando no cabe aplicar el c. 1352 §2, no es clara la situación diseñada por el c. 1335 para las penas latae sententiae no declaradas, ni es fácil tener seguridad sobre su correcta aplicación. La declaración de

${ }^{44}$ Esta remisión requiere cumplir con lo previsto en el c. 1357 §2, pero eso no impide que la remisión sea jurídicamente eficaz; e incluso hay motivos por los cuales se acepta que no se proceda a lo indicado en la mencionada norma, cf. Aspe, 184-189.

45 Para esta declaración del Pontificio Consejo, cf. Enchiridion Vaticanum 16 (1997): 436-437. Sobre esta cuestión cf. Pighin, 206-207. 
1997 deja las cosas más diáfanas para el delito del c. 1394 §1, pero no se ven razones para aplicarla a los demás; de modo que en cualquiera de ellos se podrán generar dudas y dificultades para su aplicación. De hecho, partiendo de que se refiere a un delito que, por sus características, no permanece oculto a los demás, el propio Pontificio Consejo dice en ese texto que lo más adecuado es siempre proceder a la declaración de la pena ${ }^{46}$.

Seguramente, ante algún indicio, sospecha o noticia más cierta de un delito, lo más adecuado sea ponerlo en conocimiento de la autoridad competente para que inicie las actuaciones penales previstas en la ley, que irían encaminadas a una resolución autoritativa generadora de una situación canónicamente clara que, siendo pública, en principio podría ser conocida por cualquiera. Se podría saber entonces, con la certeza que alcanzan a tener estas resoluciones, si el párroco del ejemplo anterior está sujeto o no a una pena y, en general, si es ésta o no la situación en la que queda cualquier persona sobre la que existan sospechas, rumores o dudas. En realidad, esto es lo que habría que decir y hacer en el caso de una pena ferendae sententiae, cuyos efectos son los mismos que los de una latae sententiae declarada en el caso de las penas que pueden adoptar una u otra modalidad, como son las que estamos tratando en este estudio ${ }^{47}$.

Por otro lado, las penas latae sententiae presentan algunos problemas de encaje con la propia regulación codicial en materia penal. Por ejemplo, el c. 1347 §1 dispone que «No puede imponerse válidamente una censura si antes no se ha amonestado al menos una vez al reo»; y ya sabemos que las penas latae sententiae se imponen ipso facto con la comisión del delito, de modo que se prescinde de que haya habido o no una previa amonestación. Por más que pueda ser una deducción lógica y sencilla

${ }^{46}$ Si no se hace a su debido tiempo, la situación puede complicarse cada vez más y llegar a niveles en los que no es fácil ninguna solución de las que aporta el CIC, pudiéndose necesitar medidas especiales. No habría que descartar que, en alguna medida, esto esté en la raíz, por ejemplo, de las facultades concedidas a la Congregación para el clero en 2009, cf. José Luis Sánchez-Girón. "Novedades en el tratamiento de algunos delitos cometidos por clérigos". En Retos del Derecho Canónico en la sociedad actual. Actas de las XXXI Jornadas de Actualidad Canónica, dirigido por Carmen Peña, 56-67. Madrid: Dyckinson, S. L., 2012.

47 Esta equiparación se puede apreciar a lo largo de lo que aquí se ha dicho acerca de los efectos de las penas. Por confirmar la afirmación, cf. Mosconi, "Declaración de penas", 899-900. 
de hacer, no faltan autores que consideran oportuno clarificar que esta norma solo afecta a las penas ferendae sententiae ${ }^{48}$.

Por señalar un aspecto más en el cual las penas latae sententiae presentan alguna dificultad, cabría hablar de la prescripción de la acción criminal, contemplada en el c. 1362. No acaba de quedar claro si esta prescripción impediría declarar una pena latae sententiae o si solo afectaría a la imposición de las penas ferendae sententiae ${ }^{49}$; y parece claro que, si fuera lo primero, la compleja situación que pueden crear las penas latae sententiae no declaradas podría llegar a perpetuarse en el tiempo.

\section{VALORACIONES Y CONCLUSIONES}

A partir de todo lo anterior no resultaría tan inapropiado plantearse si valdría la pena que todas las penas fueran ferendae sententiae. Ciertamente, cabe pensar en supuestos en los que una persona es plenamente consciente de haber incurrido en una pena latae sententiae y está perfectamente al tanto de lo que esto comporta cuando la pena no está declarada, además de dispuesto a someterse a sus efectos en cada circunstancia que se presente. No obstante, una situación canónica y eclesialmente compleja nunca se evitaría y, por otro lado, la finalidad no puede ponerse en el mero sometimiento a la pena (que podría llegar a ser un ejercicio de virtuosismo jurídico) sino en que mueva al arrepentimiento y a solicitar el perdón. No hay por qué negar que pueda haber casos en los cuales el diseño creado por el CIC alcance este objetivo, pero creemos haber dado

${ }^{48}$ Cf., p. ej., Michael Benz, “Comentario al canon 1347”. En Código de Derecho Canónico. Edición bilingüe, fuentes y comentario de todos los cánones, editado por Antonio Benlloch, 598. 9. a ed. Valencia: EDICEP C. B., 2001. Algún autor se hace eco de un razonamiento, que puede ser un tanto artificioso, según el cual la propia ley o precepto que establece una pena latae sententiae es ya una amonestación previa, cf. Pighin, 133.

49 Para una afirmación más clara en el primer sentido, cf. Pighin, 286-287. Para una opinión que no se manifiesta con igual determinación al respecto, cf. de Paolis y Cito, 275. Para un estudio más completo sobre la prescripción de la acción criminal, cf. José Luis Sánchez-Girón. "Algunos interrogantes en la disciplina codicial sobre la prescripción de la acción criminal”. En «Iustitia el iudicium». Studi di diritto matrimoniale e processuale canonico in onore di Antoni Stankiewicz, editado por Janusz Kowal y Joaquín Llobell, IV, 2167-2185. Cittá del Vaticano: Librería Editrice Vaticana, 2010. 
motivos para pensar que también es susceptible de generar situaciones complicadas que no benefician a la comunidad y pueden motivar incluso la apatía de la persona sujeta a la pena con respecto a regularizar su situación. Por otro lado, puede mover también a una cierta pereza de las autoridades de cara a declarar la pena, considerando que aun estando sin declarar ya produce algunos efectos; pero esto puede llevar a prolongar en el seno de la comunidad esas situaciones complejas a las que nos hemos referido.

Lo cierto es que al afrontarse la elaboración del Código vigente se planteó seriamente la posibilidad de prescindir de las penas latae sententiae $e^{50}$. Finalmente no se hizo así — aunque se redujo notablemente su número comparando con el Código anterior de $1917^{51}$ — y no faltan razones ni argumentos en favor de su presencia en el derecho de la Iglesia, el cual pide en el c. 1318 limitarlas a delitos «que puedan causar un escándalo más grave o no puedan castigarse eficazmente con penas ferendae sententiae». Se suele alegar, por ejemplo, que con estas penas se logra producir efectos penales en delitos que fácilmente permanecen ocultos y que actúan de modo semejante a como lo hace el propio Dios (haciendo que al pecado le sigan de inmediato sus consecuencias); o bien que, al dar un pleno protagonismo al autor del delito por su aplicación ipso facto ${ }^{52}$, son cauce para un propósito tan genuino del derecho canónico como es su firme voluntad de obligar en conciencia ${ }^{53}$.

Con todo, cabe señalar que el CIC no establece una pena de este tipo para un delito tan grave y generador de tanto escándalo actualmente como es el abuso sexual de un menor por parte de un clérigo - c. 1395 §2; art. 6 de las normas para delitos reservados a la Congregación para la Doctrina de la Fe (ver la nota 7)— que también es muy susceptible de permanecer oculto por mucho tiempo; y podrían encontrase otros casos en los que tal vez sería discutible que haya una adecuada aplicación de

${ }^{50}$ Así se llegó a expresar incluso en los principios directivos para la elaboración del CIC que se formularon; concretamente en el n. 9, cf. Communicationes 1 (1969): 85. Ver, también, Communicationes 9 (1977): 305.

${ }^{51}$ Cf. Pighin, 132,135.

52 Para ambas argumentaciones, cf. de Paolis y Cito, 131.

53 Sobre esta característica del derecho canónico, cf. Gianfranco Ghirlanda. Il diritto nella Chiesa mistero di comunione. 2. ${ }^{\text {a }}$ ed. Cinisello Balsamo-Milao: Edizioni San Paolo, 1993, 71. 
ese criterio ${ }^{54}$. Por otro lado, quizá se podría confiar en que establecer una pena ferendae sententiae ya es una medida jurídica con empaque y entidad penales de primer orden, capaz de producir el efecto que buscan las penas de disuadir del delito. Junto a esto, se puede tomar en consideración cuanto se ha dicho en este estudio acerca de la complejidad que generan las penas no declaradas para el propio delincuente y en la vida de la comunidad, y revalidar a partir de ahí que la opción más adecuada es siempre un pronunciamiento de la autoridad competente; es decir: la declaración de la pena latae sententiae. Bien mirado, esto viene a ser como optar por el establecimiento de penas ferendae sententiae; opción que, sin duda, debería ir acompañada por el fortalecimiento de los medios personales y materiales necesarios para que las actuaciones y los procesos penales no sean percibidos como acciones problemáticas y complicadas de aplicar, cosa que ocurre de manera bastante generalizada y ha provocado que por mucho tiempo se haya recurrido menos a ellas ${ }^{55}$.

Se puede considerar también que no falta quien estima inadecuado -incluso contrario al derecho natural-implicar al delincuente en su propia condenación y en la ejecución de su propia pena ${ }^{56}$; y se podría pensar que el remordimiento moral ha de bastar para mover al arrepentimiento, a pedir perdón y a reparar los daños y el escándalo en cuanto sea posible, sin necesidad de considerar tan importante intensificar la motivación hacia ello haciendo entrar en juego el escenario penal, máxime cuando, como hemos visto, esto se produce generando situaciones canónicas complejas y de efectos ambivalentes. Finalmente, digamos que el Código de Cánones de las Iglesias Orientales de 1990 ha prescindido de las penas latae sententiae, lo cual no es un argumento menor en el que pensar dentro del contexto de cuanto estamos viendo.

En definitiva, no cabe negar que hay razones para sostener el sentido de estas penas y la opción por disponer de ellas en la Iglesia. El hecho de ser un instituto que desconocen los demás ordenamientos jurídicos puede incomodar la necesidad de que el derecho canónico no sea irreconocible como tal en el contexto de los demás; pero es igualmente importante que

${ }^{54}$ Pensemos, por ejemplo, que la herejía tiene establecida una pena latae sententiae (c. 1364) al tiempo que está concebida, según el c. 1330, como un delito que solo se consuma cuando es conocido por otros. A este respecto, cf., p. ej., Woestman, 100.

55 Cf. Josemaría Sanchís. "Comentario al canon 1314". En Comentario exegético IV/1: 267.

56 Cf. Pighin, 133. 
sea un ordenamiento sui generis en ese entorno ${ }^{57}$, y estas penas colaborarían a ello teniendo su fundamento no en cuestiones artificiosas y banales sino en aspectos radicalmente cristianos. En todo caso, tampoco hay que pasar por alto los argumentos contrarios a las mismas ni la problemática que entraña, en concreto, la regulación que hace de ellas el vigente CIC; en particular, lo que se refiere a las penas no declaradas. La solidez de un ordenamiento jurídico no se debe confiar a un sometimiento que excluya el análisis crítico del mismo en los contextos donde es apropiado hacerlo. Conscientes de estar en uno de ellos, hemos intentado aportar elementos para una visión más detallada y concreta de la cuestión que contribuyan, aunque sea en la modestia de nuestra capacidad, a profundizar ese análisis y ayuden a obtener conclusiones más sólidas y a tomar decisiones, sean cuales sean, con mayor seguridad y convicción.

\section{REFERENCIAS}

Aspe, Roberto. "El 'caso urgente' para la remisión de las censuras en la normativa canónica actual”. Periodica 101 (2012): 259-198.

Aznar, Federico. "Comentario al canon 1333". En Código de Derecho Canónico. Edición bilingüe comentada por los profesores de Derecho Canónico de la Universidad Pontificia de Salamanca, 701. 15. . ed. Madrid: BAC, 1999.

Aznar, Federico. “Comentario al canon 1384”. En Código de Derecho Canónico. Edición bilingüe comentada por los profesores de Derecho Canónico de la Universidad Pontificia de Salamanca, 724. 15. ${ }^{\text {a }}$ ed. Madrid: BAC, 1999.

Bernal, José. "Comentario al canon 1332". En Comentario exegético al Código de Derecho Canónico, dirigido por Ángel Marzoa, Jorge Miras, y Rafael Rodríguez-Ocaña, vol. IV/1, 361-363. 3. ${ }^{\text {e ed. Barañáin-Nava- }}$ rra: EUNSA, 2002.

Benz, Michael. "Comentario al canon 1347”. En Código de Derecho Canónico. Edición bilingüe, fuentes y comentario de todos los cánones, dirigi-

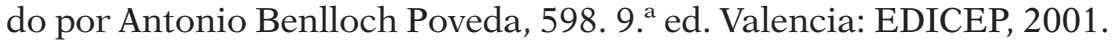

${ }^{57}$ Cf. Antonio M. Rouco y Eugene Corecco. "Sacramento y Derecho: ¿Antinomia en la Iglesia? Reflexiones para una Teología del Derecho Canónico”. En Teología y Derecho, Antonio M. Rouco, 62. Madrid: Ediciones Cristiandad, 2003. 
Berçaitz de Boggiano, Ana Lía. "Peligro de muerte". En Diccionario General de Derecho Canónico, dirigido por Javier Otaduy, Antonio Viana, y Joaquín Sedano, vol. VI, 65-69. Cizur Menor, Navarra: Universidad de Navarra-Thomson Reuters Aranzadi, 2012.

Boutros, Norman. Aspetti giuridico-teologici delle sanzioni e delle pene canoniche alla luce dell'Ecclesiologia di comunione del Concilio Ecumenico Vaticano II. Roma: Pontificia Università Lateranense, 2002.

Calabrese, Antonio. "Comentario al canon 1383". En Comentario exegético al Código de Derecho Canónico, dirigido por Ángel Marzoa, Jorge Miras, y Rafael Rodríguez-Ocaña, vol. IV/I, 546-548. 3. ${ }^{\text {e ed. Barañáin-Na- }}$ varra: EUNSA, 2002.

Garczarek, Wieslaw. "La sospensione penale (cc. 1333-1334) nel Codex Iuris Canonici del 1983". Apollinaris 76 (2003): 359-399.

Ghirlanda, Gianfranco. Il diritto nella Chiesa mistero di comunione. 2. ${ }^{a}$ ed. Cinisello Balsamo-Milao: Edizioni San Paolo, 1993.

Marzoa, Ángel. “Comentario al canon 1323”. En Comentario exegético al Código de Derecho Canónico, dirigido por Ángel Marzoa, Jorge Miras, y Rafael Rodríguez-Ocaña, vol. IV/I, 306-307. 3. a ed. Barañáin-Navarra: EUNSA, 2002.

Mattia, Giuseppe di. "Comentario al canon 1393". En Comentario exegético al Código de Derecho Canónico, dirigido por Angel Marzoa, Jorge Miras, y Rafael Rodríguez-Ocaña, vol. IV/1, 575-576. 3. a ed. Barañáin-Navarra: EUNSA, 2002.

Mosconi, Mario. "Declaración de penas”. En Diccionario General de Derecho Canónico, dirigido por Javier Otaduy, Antonio Viana, y Joaquín Sedano, vol. II, 897-901. Cizur Menor, Navarra: Universidad de Navarra-Thomson Reuters Aranzadi, 2012.

Olivares, Estanislao. "Sacramentale". En Nuovo Dizionario di Diritto Canonico, dirigido por Carlos Corral, Velasio de Paolis, y Gianfranco Ghirlanda, 939-940. 2. ${ }^{\mathrm{a}}$ ed. Cinisello Balsamo-Milano: Edizioni San Paolo, 1996.

Papale, Claudio. "Latae sententiae (penas)". En Diccionario General de Derecho Canónico, dirigido por Javier Otaduy, Antonio Viana, y Joaquín Sedano, vol. IV, 975-977. Cizur Menor, Navarra: Universidad de Navarra-Thomson Reuters Aranzadi, 2012.

Paolis, Velasio de, y Davide Cito. Le sanzioni nella Chiesa. Commento al Codice di Diritto Canonico Libro VI. 2. ${ }^{a}$ ed. Città del Vaticano: Urbaniana University Press, 2001. 
Pighin, Bruno F. Diritto penale canonico. Venezia: Marzianum Press, 2008. Renken, John A. The Penal Law of the Roman Catholic Church. Commentary on Canons 1311-1399 and 1717-1731 and Other Sources of Penal Law. Ottawa: Saint Paul University, 2015.

Rouco, Antonio M., y Eugene Corecco. "Sacramento y Derecho: ¿Antinomia en la Iglesia? Reflexiones para una Teología del Derecho Canónico". En Teología y Derecho, Antonio M. Rouco, 23-80. Madrid: Ediciones Cristiandad, 2003.

Sánchez-Girón, José Luis. "El Superior que establece la pena: valoración crítica en clave exegética de los cc. 1333 §3.1 y 1338 §1”. Estudios Eclesiásticos 90 (2015): 683-700.

Sánchez-Girón, José Luis. "Penas medicinales y expiatorias: Una alternativa en la que profundizar entre otros aspectos penales del CIC". En El Código de Derecho Canónico de 1983. Balance y perspectivas a los 30 años de su promulgación, dirigido por José Luis Sánchez-Girón y Carmen Peña, 270-295. Madrid: Universidad Pontificia Comillas, 2014. Sánchez-Girón, José Luis. "Novedades en el tratamiento de algunos delitos cometidos por clérigos". En Retos del Derecho Canónico en la sociedad actual. Actas de las XXXI Jornadas de Actualidad Canónica, dirigido por Carmen Peña, 55-70. Madrid: Dykinson, 2012.

Sánchez-Girón, José Luis. "Pena reservada". En Diccionario General de Derecho Canónico, dirigido por Javier Otaduy, Antonio Viana, y Joaquín Sedano, vol. VI, 85-88. Cizur Menor, Navarra: Universidad de Navarra-Thomson Reuters Aranzadi, 2012.

Sánchez-Girón, José Luis. "Algunos interrogantes en la disciplina codicial sobre la prescripción de la acción criminal”. En «Iustitia el iudicium». Studi di diritto matrimoniale e processuale canonico in onore di Antoni Stankiewicz, dirigido por Janusz Kowal, y Joaquín Llobell, vol. IV, 2167-2185. Cittá del Vaticano: Librería Editrice Vaticana, 2010.

Sánchez-Girón, José Luis. "Delitos contemplados en las normas de graviorubus delictis del año 2010”. Estudios Eclesiásticos 85 (2010): 731-767.

Sanchís, Josemaría. "Comentario al canon 1314". En Comentario exegético al Código de Derecho Canónico, dirigido por Ángel Marzoa, Jorge Miras, y Rafael Rodríguez-Ocaña, vol. IV/1, 265-267. 3. ${ }^{\text {a ed. Bara- }}$ ñáin-Navarra: EUNSA, 2002.

Urru, Angelo G. Punire per salvare. Il sistema penale nella Chiesa. Roma: Edizioni Vivere in, 2001. 
Woestman, William H. Ecclesiastical Sanctions and the Penal Process. 2. ${ }^{a}$ ed. Otawa: St. Paul University, 2003.

Suchecki, Zbigniew. Le privazioni e le proibizioni nel Codice di Diritto Canonico del 1983. Roma: Librería Editrice Vaticana, 2010. 